\title{
Non-Clinical Specialty Nurse
}

National Cancer Institute

\section{Source}

National Cancer Institute. Non-Clinical Specialty Nurse. NCI Thesaurus. Code C20854.

Professions that require the skills and experiences of nurses, but do not require actual patient contact on a regular basis. 